\title{
Antidepressant blood levels in acute overdose
}

\author{
C. Hallstrom* \\ M.B., M.R.C.P., D.P.M., M.R.C.Psych. \\ L. GIFFORD \\ B.Sc., Ph.D., C.Chem., M.R.I.C.

\begin{abstract}
St Leonard's Hospital, Nuttall Street, London, N.1, and Department of Clinical Pharmacology, St Bartholomew's Hospital, London EC1A $7 B E$
\end{abstract}

\begin{abstract}
Summary
Plasma antidepressant levels and clinical condition were measured sequentially for at least $24 \mathrm{hr}$ in eight patients who presented with acute antidepressant overdosage. There was no evidence to suggest that a knowledge of the drug plasma levels had anything to offer in the management of a patient whose overdose included a tricyclic antidepressant.
\end{abstract}

\section{Introduction}

Tricyclic antidepressants are widely prescribed drugs and feature prominently as agents used in self poisoning. A wide range of complications in overdose have been recognized: cardiac conduction disturbances and arrhythmias; respiratory depression; convulsions; hyperpyrexia and psychosis. Death can also occur (Sedal et al., 1972; Asberg et al, 1971). Interest has recently been aroused in the relationship between plasma levels of antidepressants and the various expressions of their effect. Considerable individual variation in plasma levels of drug have been demonstrated for a fixed oral dose, and plasma levels show a closer correlation with pharmacological action than does oral dose. Debate at present exists as to the precise significance of the plasma drug level related to the therapeutic response, but therapeutic levels of amitriptyline are rarely encountered above $200 \mathrm{ng} / \mathrm{ml}$ (Asberg et al., 1971; Braithwaite et al., 1972).

Any possible relationships between the plasma antidepressant levels and the physiological measures made on patients who presented with overdoses were investigated.

\section{Method}

Eight patients who had taken tricyclic antidepressant overdoses were studied. Blood was taken on admission and at approximately 6,12 and $24 \mathrm{hr}$ after. At the same time, a rating form was completed with special reference to severity of disturbances of consciousness. Temperature, pulse rate,

* Present address: The Maudsley Hospital, Denmark Hill, London SE5 8AZ.
ECG abnormalities and any other relevant findings were noted. The plasma was deep frozen and subsequently analysed by gas chromatography (Gifford, Turner and Pare, 1975).

\section{Results}

The condition of four patients was critical on general clinical grounds. They required supportive measures and were deeply unconscious for about $18 \mathrm{hr}$. In four of the eight patients the fall in plasma levels followed that of returning consciousness. In two patients the correlation was poor and in two the clinical condition deteriorated as the plasma drug level fell. There was no correlation between the plasma drug level and the clinical severity of the overdose, ECG changes, variations in temperature, pulse rate change, or anticholinergic side effects on return to consciousness. Ventricular ectopic beats occurred for the first time in a patient at a drug concentration of $320 \mathrm{ng} / \mathrm{ml}$, the level having fallen from $510 \mathrm{ng} / \mathrm{ml}$ since admission.

All patients showed a reduction of plasma drug levels within $20 \mathrm{hr}$ but gastric lavage even in the first $3 \mathrm{hr}$ after drug ingestion did not prevent a further rise in plasma drug level. Plasma nortriptyline levels in no case rose above $50 \mathrm{ng} / \mathrm{ml}$.

\section{Conclusion}

In half the patients the clinical condition improved as plasma drug level fell. Otherwise there was no correlation between plasma drug levels or their change with any of the parameters measured.

There was, therefore, no evidence to suggest that knowledge of plasma drug levels or sequential levels have anything to offer in the management of a patient whose overdose included a tricyclic antidepressant.

\section{Acknowledgments}

We should like to thank Professor P. Turner, Dr C. M. B. Pare and Dr J. V. Collins for their advice and encouragement and L.A.G. wishes to thank Geigy Pharmaceuticals for financial support. 
TABLE 1. Synopsis of significant findings

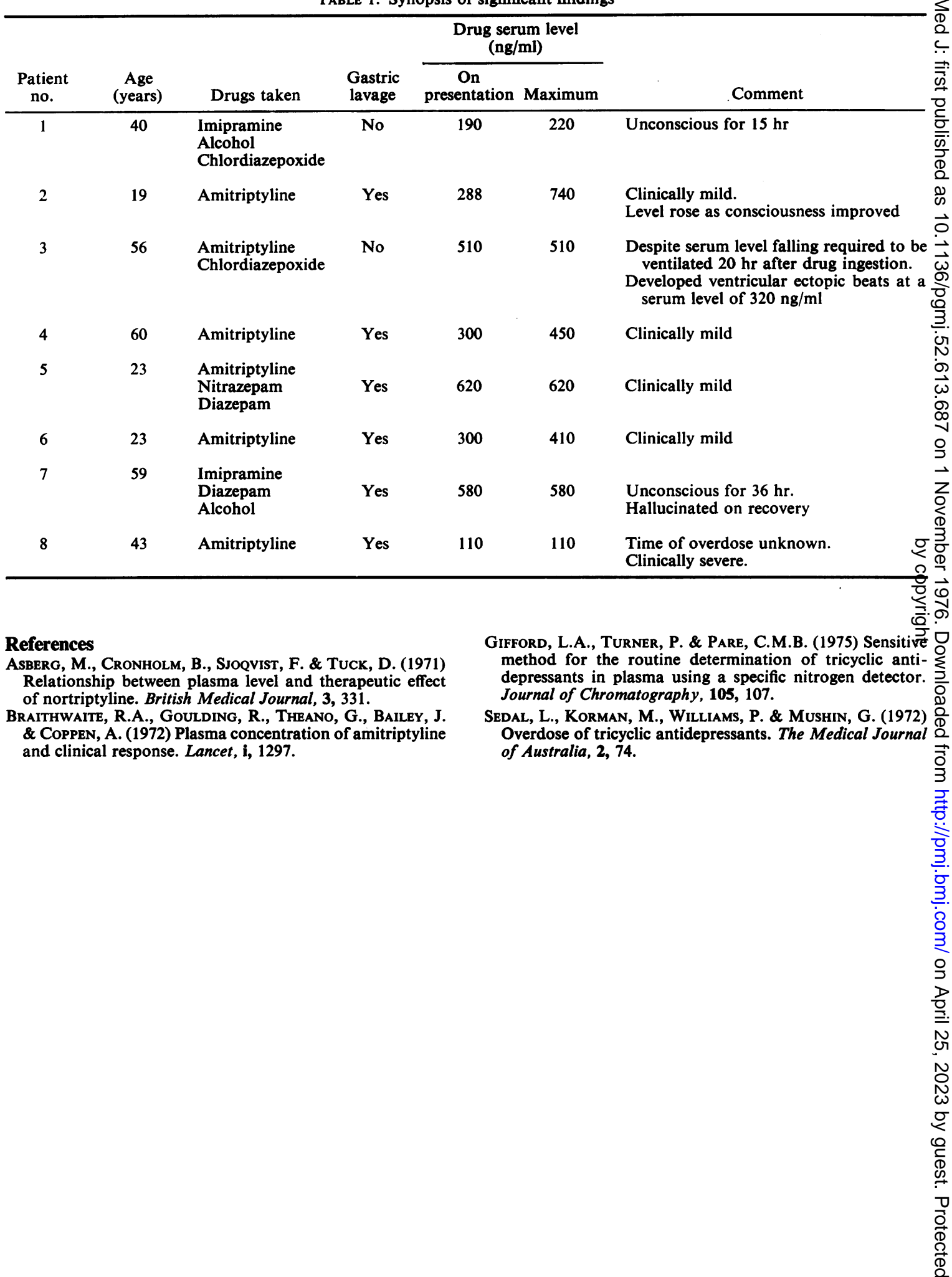

